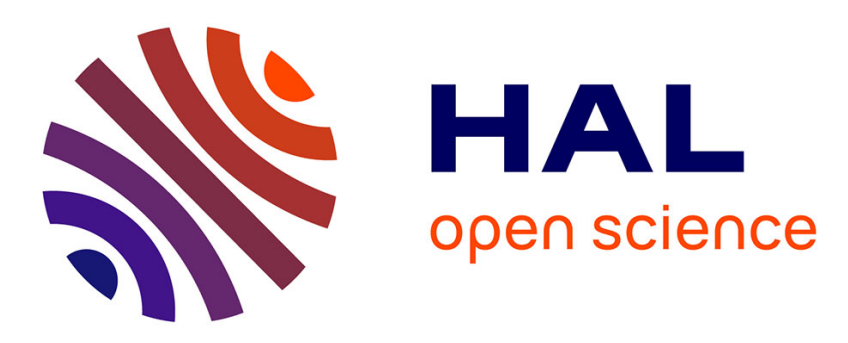

\title{
Nano-vanadium pentoxide films for electrochromic displays
}

Issam Mjejri, Laura Maria Manceriu, Manuel Gaudon, Aline Rougier, Faouzi Sediri

\section{To cite this version:}

Issam Mjejri, Laura Maria Manceriu, Manuel Gaudon, Aline Rougier, Faouzi Sediri. Nanovanadium pentoxide films for electrochromic displays. Solid State Ionics, 2016, 292, pp.8-14. 10.1016/j.ssi.2016.04.023 . hal-01323332

\section{HAL Id: hal-01323332 \\ https://hal.science/hal-01323332}

Submitted on 1 Feb 2021

HAL is a multi-disciplinary open access archive for the deposit and dissemination of scientific research documents, whether they are published or not. The documents may come from teaching and research institutions in France or abroad, or from public or private research centers.
L'archive ouverte pluridisciplinaire HAL, est destinée au dépôt et à la diffusion de documents scientifiques de niveau recherche, publiés ou non, émanant des établissements d'enseignement et de recherche français ou étrangers, des laboratoires publics ou privés. 


\section{Nano-vanadium pentoxide films for electrochromic displays}

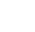

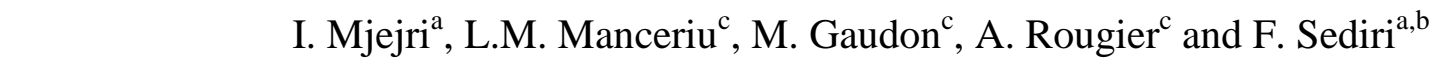

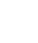

${ }^{a}$ Unité Matériaux et Environnement IPEIT, Université de Tunis, 2 rue JawaherLel Nehru

$$
\text { 1008, B. P. } 229 \text { Montfleury Tunis, Tunisie }
$$

${ }^{b}$ Faculté des Sciences de Tunis, Université de Tunis El Manar, 2092 El Manar Tunis, Tunisie

${ }^{c}$ CNRS, Université de Bordeaux, ICMCB, 87 Avenue du Dr. Albert Schweitzer, F-33608

Pessac, France

\section{Abstract}

We demonstrate the benefit of home-made nanopowder precursors on the electrochromism of $\mathrm{V}_{2} \mathrm{O}_{5}$ films deposited by the "Doctor Blade" method. Using the polyol process, nano-structured $\mathrm{V}_{2} \mathrm{O}_{5}$ powder were synthesized. Orthorhombic $\mathrm{V}_{2} \mathrm{O}_{5}$ thin films deposited from as-synthesized powder exhibit good cycling stability associated with significant reflectance modulation in both lithium and sodium based electrolytes. The orange to green reversible color change appears well suitable for display application. To conclude, the electrochromic performances of complete devices using $\mathrm{WO}_{3}$ as complementary electrode and 0.3 M Lithium Bis(Trifluoromethanesulfonyl)Imide LiTFSI in BMITFSI plastified with polymethylmetacrylate (PMMA) membrane electrolyte are reported.

Keywords: Polyol synthesis, Vanadium pentoxide, Electrochromic performances, Devices. 


\section{Introduction}

Electrochromism is a phenomenon in which materials and devices are able to change their optical properties in a reversible and persistent way under an applied voltage [1-4].The applications of electrochromic devices, ECDs, are multifold from smart windows in cars and buildings to spacecraft thermal control, as transmittive or reflective properties and visible or infrared domain are concerned. Among varieties of electrochromic materials, transition metal oxides have received special interest [5] partially due to their higher stability as compared to organic EC. The modification of the optical properties often results from an insertion of small ions (i.e; $\mathrm{H}^{+}$or $\mathrm{Li}^{+}$) associated with reversible redox reactions between the different valence states of the metal. Tungsten trioxide, $\mathrm{WO}_{3}$, remains by far the typical electrochromic inorganic material, switching to a blue color upon reduction and cation insertion. For practical use and device construction, $\mathrm{WO}_{3}$ needs to be associated with complementary oxides. If anodically colored $\mathrm{IrO}_{\mathrm{x}}[6-8]$ and $\mathrm{NiO}$ [9-13] based thin films, have been largely studied, $\mathrm{V}_{2} \mathrm{O}_{5}$ appears to be an interesting alternative candidate. Indeed, orthorhombic $\mathrm{V}_{2} \mathrm{O}_{5}$ has been investigated for a number of applications, such as lithium batteries, in respect of its layered structure with good cation intercalation ability and low voltage required $[14,15]$. Due to their layered structures, intercalation of sodium into the structure of $\mathrm{V}_{2} \mathrm{O}_{5}$ has been investigated for novel applications in sodium ion batteries [16]. To our knowledge, the electrochromic properties in $\mathrm{V}_{2} \mathrm{O}_{5}$ associated with $\mathrm{Na}$ insertion has not yet been reported.

$\mathrm{V}_{2} \mathrm{O}_{5}$ exhibits both anodic and cathodic electrochromism properties and multicolor display [17]. However, the lithiation processes in $\mathrm{V}_{2} \mathrm{O}_{5}$ bulk are relatively slow because the low electric conductivity $\left(10^{-3}-10^{-2} \mathrm{~S}^{-1}\right)$ and the low $\mathrm{Li}^{+}$diffusion coefficients $\left(10^{-13}-10^{-}\right.$ ${ }^{12} \mathrm{~cm}^{2} . \mathrm{s}^{-1}$ ) [18-20]. In comparison with $\mathrm{V}_{2} \mathrm{O}_{5}$ bulk, the nanostructured of $\mathrm{V}_{2} \mathrm{O}_{5}$ is characterized by a large electrochemical surface area and good interconnectivity for electronic conductivity [21]. The electrochromic performance of vanadium pentoxide depends on several parameters 
including the pore size of intercalation sites, the film thickness and the deposition method. Several methods, including pulsed laser deposition [22], vacuum evaporation [23, 24], thermal evaporation [25], sputtering [26], ultrasonic spraying [27] and sol-gel [28], have been used for the deposition of $\mathrm{V}_{2} \mathrm{O}_{5}$ thin films. Nearly all of them deal with transparent thin films whereas the properties of non-transparent "thick" films remains poorly investigated. In addition, the performance of the electrochromic materials is directly related to the penetration depth of the cations and the accessibility of the electroactive sites, thus explaining the growing interest for nanomaterials.

Herein, nano-sized vanadium pentoxide powders were synthesized by the polyol method. Focusing on EC displays as application, mainly correlated to a modulation of the reflectance, micrometer thick films were prepared from the as-synthesized $\mathrm{V}_{2} \mathrm{O}_{5}$ nanopowders using a simple and cost effective method, namely Doctor Blade, at low temperatures $\left(150{ }^{\circ} \mathrm{C}\right)$, suitable even for plastic or paper substrates.

Finally, the electrochromic activity of $\mathrm{V}_{2} \mathrm{O}_{5}$ films is reported both in lithium and sodium based electrolytes, while their integration in a complete device shows good optical reflectance modulation, nice cyclability and stability. The current results encourage future research in the area of multicolored (flexible) displays based on inorganic EC.

\section{Experimental details}

\section{Polyol synthesis of $\mathrm{V}_{2} \mathrm{O}_{5}$ powder and characterization}

All of the chemical reagents were purchased from Acros Organics and utilized without further purification. Ammonium metavanadate $\left(\mathrm{NH}_{4} \mathrm{VO}_{3}\right)$ was used as vanadium source and ethylene glycol $\left(\mathrm{H}_{6} \mathrm{C}_{2} \mathrm{O}_{2}\right)$ as template. In a typical synthesis, $\mathrm{NH}_{4} \mathrm{VO}_{3}(1.669 \mathrm{~g})$ was added to $100 \mathrm{~mL} \mathrm{H}_{6} \mathrm{C}_{2} \mathrm{O}_{2}$. The resulting mixture was heated to $70{ }^{\circ} \mathrm{C}$ under continuous stirring to obtain a yellow sol which was then transferred into a $100 \mathrm{~mL}$ glass flask and refluxed at 170 
${ }^{\circ} \mathrm{C}$ for $3 \mathrm{~h}$. At the end of the reaction, a vanadylglycolate (VEG) precipitate was obtained. The precipitate was centrifuged and washed several times with ethanol to remove the organic product and dried in an oven at $80{ }^{\circ} \mathrm{C}$. To prepare the final $\mathrm{V}_{2} \mathrm{O}_{5}$ powder, the VEG precursors were calcined for $2 \mathrm{~h}$ at $500{ }^{\circ} \mathrm{C}$. This method in which the polyol serves as both the solvent and the reducing agent, offers several advantages as compared to other chemical methods. Indeed, the polyol process is commonly considered as an energy efficient and environmentally benign process, also allowing the preparation of large quantity of powders. The powder structure was characterized by X-ray diffraction analysis (Philips PW 1820, PANalyticalX'Pert instrument, $2 \theta$ range from 8 to $80^{\circ}$ and $\lambda_{\mathrm{CuK \alpha 1}}=1.54056 \AA$ ). Scanning electron microscopy (SEM) and transmission electron microscopy (TEM) images were recorded with a SEI instrument (operating at $5 \mathrm{kV}$ ) microscope and JEOL JSM-6700F (operating at $5 \mathrm{kV}$ ) microscope, respectively.

\section{Film preparation and characterization}

$\mathrm{V}_{2} \mathrm{O}_{5}$ films were deposited by the "Doctor Blade" method from home-made powder, synthesized by the polyol method. Firstly $0.725 \mathrm{~g}$ of powder was dispersed into $2.5 \mathrm{ml}$ distilled water and acetyl acetone (AcAc). The resulting dilute was stirred for $12 \mathrm{~h}$ at room temperature and after aliquots of the as-prepared colloidal $\mathrm{V}_{2} \mathrm{O}_{5}$ solution were deposited on the ITO $\left(\mathrm{In}_{2} \mathrm{O}_{3}: \mathrm{Sn}\right)$ coated glass. After deposition, $\mathrm{V}_{2} \mathrm{O}_{5}$ thin films were dried at $150{ }^{\circ} \mathrm{C}$ for 3 $\mathrm{h}$ to eliminate organic products and ensure adhesion to the substrates. The thickness of the $\mathrm{V}_{2} \mathrm{O}_{5}$ films, measured using a Dektak mechanical profilometer, was of about $3.9 \pm 0.2 \mu \mathrm{m}$. The films structure was characterized by X-ray diffraction (XRD) analysis (Philips PW 1820, PANalyticalX'Pert instrument, $2 \theta$ range from 8 to $80^{\circ}$ and $\lambda_{\text {CuKal }}=1.54056 \AA$ ). The morphology of the layers was investigated using a JEOL JSM-840 (operating at $15 \mathrm{kV}$ ) microscope. 


\section{Electrochromic measurements}

Electrochemical measurements of $\mathrm{V}_{2} \mathrm{O}_{5}$ films on ITO/glass were carried out in a three electrodes cell configuration using a BioLogic SP50 potentiostat/galvanostat apparatus. The counter-electrode and reference electrode consisted of a platinum foil and Saturated Calomel Electrode, $\mathrm{SCE}\left(\mathrm{E}_{\mathrm{SCE}}=0.234 \mathrm{~V} / \mathrm{ENH}\right)$, respectively. The operating voltage was controlled between $-0.4 \mathrm{~V}$ and $1.8 \mathrm{~V}$ at different scan rates, from 2 to 50 $\mathrm{mV} / \mathrm{s}$, in both lithium and sodium based electrolytes, namely $0.3 \mathrm{M}$ lithium bistrifluoromethanesulfonimide (LiTFSI, Solvionic, purity>99.99\%) in 1-butyl-3methylimidazoliumbis-(trifluoromethanesulfonyl)-imide (BMITFSI) and sodium bis(trifluoromethanesulfonate)-imide (NaTFSI, Solvionic, purity> 99.99\%)in 1-butyl-3methylimidazoliumbis-(trifluoromethanesulfonyl)-imide (BMITFSI). All the electrochemical measurements were performed at room temperature. The optical reflectance of $\mathrm{V}_{2} \mathrm{O}_{5}$ thin films was measured in situ using a Varian Cary 5000 UV-VisNIR spectrophotometer. The film reflectance was also analyzed using a Konica Minolta CM700D spectrophotometer allowing the direct determination of colorimetric parameters in the CIE L*a*b* colorimetric space. The optical contrast $\left(\Delta \mathrm{E}^{*}\right)$ between two color states was calculated following the equation:

$$
\Delta \mathrm{E}^{*}=\left[\left(\mathrm{L}^{*}{ }_{1}-\mathrm{L}^{*}\right)^{2}+\left(\mathrm{a}^{*}{ }_{1}-\mathrm{a}_{2}\right)^{2}+\left(\mathrm{b} *_{1}-\mathrm{b}^{*}\right)^{2}\right]^{1 / 2} \quad \text { (eq.1) }
$$

\section{Results and discussion}

\section{1. $\mathrm{V}_{2} \mathrm{O}_{5}$ powders}

The crystallinity of the orange powder synthesized by the polyol process before and after calcination was studied by XRD. Before calcination, the XRD pattern (Fig. 1a) indicates that the d-spacing values of all diffraction peaks are identical to those of the VEG (JCPDS No 49-2497) with space group C2/c. After calcination (Fig. 1b), the XRD pattern reveals the 
presence of narrow peaks, suggesting a material with high crystallinity. The d-spacing values of all diffraction peaks are identical to those of the orthorhombic crystalline phase $\mathrm{V}_{2} \mathrm{O}_{5}$ (Space Group: Pmmn) with lattice constants $a=3.564 \AA, b=11.510 \AA$ and $c=4.373 \AA$ (JCPDS \# 85-0601). No peak of any other phase or impurity was detected from the XRD pattern showing that $\mathrm{V}_{2} \mathrm{O}_{5}$ with high purity can be synthesized via polyol synthesis at $170{ }^{\circ} \mathrm{C}$ for $3 \mathrm{~h}$. The average crystallite size was calculated using the Scherrer's formula [29]:

$$
L=0.89 \lambda / \beta \cos \theta \quad \text { (eq. 2) }
$$

Where $L$ is the average crystallite size in $\mathrm{nm}, \lambda=0.154056 \mathrm{~nm}, \beta$ is the full width at the half maximum and $\theta$ is the diffraction angle. The average crystallite size value, calculated from three of the main peaks of the XRD pattern is about $86 \mathrm{~nm}$.

The SEM and TEM micrographs (Fig. 2) show that the morphology of the assynthesized $\mathrm{V}_{2} \mathrm{O}_{5}$ powder is homogenous. At low magnification (Fig. 2a), packs of quasispherical agglomerates with individual size of about 2-3 $\mu \mathrm{m}$ diameter are visible. At intermediate magnification, hierarchical structuration is observed: the agglomerates are constituted from the assembly of over-micrometric crystallite strands or acicular platelets (Fig. 2b). The TEM images (Figs. 2c, d) captured on the few non-agglomerated crystallites show various crystallite sizes ranging from about $50 \mathrm{~nm}$ to $150 \mathrm{~nm}$, i.e. in good agreement with the average crystallite size extracted from X-ray diffraction patterns.

\section{Structure and morphology of the $\mathrm{V}_{2} \mathrm{O}_{5}$ films}

The SEM analysis of the $\mathrm{V}_{2} \mathrm{O}_{5}$ film (Fig. 3a and b) shows that the Doctor Blade process appears to induce a lamellar structure; indeed, the films resemble to a collection of micrometric plates with dimension of about $5 \mu \mathrm{m} \times 2 \mu \mathrm{m}$. Moreover, is has to be noted that the obtained films are very porous with pore diameters about $100 \mathrm{~nm}$. Such a morphology, exhibiting a large surface exchange with the electrolytes and a high light diffusion (Mie 
diffusion regime), is adequate besides electrochromic requirements for high efficiency for colored displays. The films are opaque and allow easy-alkaline elements insertion. The XRD pattern of the as-deposited $\mathrm{V}_{2} \mathrm{O}_{5}$ film shows in first approximation similar features as the powder (Fig. 4). Indeed, the $d$-spacing values of all diffraction peaks match the ones of the orthorhombic crystalline phase (JCPDS \# 85-0601) and of the ITO substrate (JCPDS \# 441087). Strong and sharp diffraction peaks indicate comparable crystallinities between the $\mathrm{V}_{2} \mathrm{O}_{5}$ films and the as-synthesized powder. No peak of any other phase or impurity was detected from the XRD pattern. However, preferential orientation of the $\mathrm{V}_{2} \mathrm{O}_{5}$ film is clearly detected along the (001) crystallographic direction. This observation is in good agreement with the lamellar morphology observed by SEM analyses. Moreover, the observation of such a preferential orientation for the $\mathrm{V}_{2} \mathrm{O}_{5}$ films obtained from a powder with isotropic crystallite shapes is very interesting but not trivial to interpret. Our hypothesis is that the hierarchical structuration previously observed on the powder is associated with coalescence of the crystallites from preferred surface orientations. This powder structuration is then preserved during the coating step. Same coalescence phenomenon was also observed by Z. Tong et al [19].

\section{Electrochromic properties of $\mathrm{V}_{2} \mathrm{O}_{5}$ films}

The repetitive cycling of $\mathrm{V}_{2} \mathrm{O}_{5}$ film in $(0.3 \mathrm{M})$ LiTFSI-BMITFSI at a scan rate of 20 $\mathrm{mV} / \mathrm{s}$ shows good reversibility, cyclability and stability in terms of capacity illustrated up to 50 cycles (Fig. 5). In agreement with a nice reversible process, the charges deduced from the $\mathrm{CVs}$ in reduction and in oxidation are equal $\left(\mathrm{Q}_{\text {red }} / \mathrm{Q}_{\mathrm{ox}}=99 \%\right)$. The insertion process of $\mathrm{Li}^{+}$ ions intercalation/deintercalation in electrochromic $\mathrm{V}_{2} \mathrm{O}_{5}$ films can be represented by the following equation:

$$
\mathrm{V}_{2} \mathrm{O}_{5}(\text { Orange })+\mathrm{xLi}^{+}+\mathrm{xe}^{-} \rightleftharpoons \mathrm{Li}_{\mathrm{x}} \mathrm{V}_{2} \mathrm{O}_{5}(\text { Green })
$$


The number of exchanged electron (x) involved during each coloration/bleaching process was estimated using the following equation:

$$
\mathrm{Q}=\mathrm{F} \cdot \mathrm{n}\left(\mathrm{V}_{2} \mathrm{O}_{5}\right) \cdot \mathrm{x}
$$$$
\text { (eq. 4) }
$$

Where $\mathrm{Q}$ is the electrochemical capacity, $\mathrm{F}=96500 \mathrm{C}$ and $\mathrm{n}$ is number of moles. The $\mathrm{x}$ values calculated from $\mathrm{V}_{2} \mathrm{O}_{5}$ from homemade powder thin films is about 0.10 , which remains quite low and may suggest that the involved process is not as simple as a common insertion process. A decrease in scan rate from $50 \mathrm{mV} / \mathrm{s}$ to $5 \mathrm{mV} / \mathrm{s}$ is associated with a progressive evolution of the CV shape corresponding to the appearance of peaks, of which resolution increases (Fig. 6a). Besides, the peaks exhibit a better signature in oxidation/anodic scan as compared to reduction/cathodic scan. The anodic maximum current density $\left(\mathrm{j}_{\mathrm{a}}\right)$ exhibits a linear relation with the square root of scanning rate $\left(\mathrm{V}^{1 / 2}\right)$ (Fig. 6b).The diffusion coefficient D of lithium ions $\left(\mathrm{Li}^{+}\right)$was calculated using Randles-Sevcik equation [30, 31]:

$$
\mathrm{J}_{\mathrm{a}}=2.6910^{5} \mathrm{n}^{3 / 2} \mathrm{AD}^{1 / 2} \mathrm{Cv}^{1 / 2}
$$

Where $\mathrm{j}_{\mathrm{a}}$ is the anodic maximum current density at oxidation state, $\mathrm{n}$ is the number of electrons transferred, A is the electrode area $\left(\mathrm{cm}^{2}\right), \mathrm{D}$ is the diffusion coefficient $\left(\mathrm{cm}^{2} / \mathrm{s}\right), \mathrm{C}$ is the concentration of the electrolyte $\left(\mathrm{mol} / \mathrm{cm}^{3}\right)$, and $\mathrm{v}$ is the voltage scan rate $(\mathrm{V} / \mathrm{s})$. The linear relation is expected for a diffusion-controlled process allowing the determination of the diffusion coefficient, $\mathrm{D}_{\mathrm{Li}}{ }^{+}=6.1 * 10^{-9} \mathrm{~cm}^{2} / \mathrm{s}$. This value is in the order, even slightly higher than the one recently reported for 3-dimensionally ordered macroporous vanadium oxides [20]. This very good electrochemical performance is ascribed to the unique highly porous hierarchical plate-like architecture that could easily facilitate electrolyte penetration and $\mathrm{Li}^{+}$ diffusion.

The diffuse reflectance spectra of $\mathrm{V}_{2} \mathrm{O}_{5}$ films corresponding to the oxidized and reduced states, registered before and after $100 \mathrm{CA}$ cycles are illustrated in Figure 7 . The $\mathrm{V}_{2} \mathrm{O}_{5}$ films switch reversibly in-between a reduced green state $(-0.4 \mathrm{~V} / 120 \mathrm{~s})$ and an oxidized-orange state 
$(+1.8 \mathrm{~V} / 120 \mathrm{~s})$ associated with reflectance values of about $4 \%$ and $24 \%$ at $630 \mathrm{~nm}$, respectively leading to an optical reflectance modulation, $\Delta \mathrm{R}$, of about $20 \%$. The stability of the optical modulation is demonstrated up to 100 cycles.

In CIE colorimetric space, the color is represented by three parameters: a luminance axis $\left(\mathrm{L}^{*}\right)$, and two hue axes $\left(\mathrm{a}^{*}\right)$ and $\left(\mathrm{b}^{*}\right)$, which can be used to define and compare quantitatively the colors. The relative luminance $\left(\mathrm{L}^{*}\right)$, the hue $\left(\mathrm{a}^{*}\right)$ and $\left(\mathrm{b}^{*}\right)$ values of $\mathrm{V}_{2} \mathrm{O}_{5}$ films in different states were measured. Indeed, for the green-reduced state (at $-0.4 \mathrm{~V}$ ) the $\mathrm{L} * \mathrm{a} * \mathrm{~b} *$ parameters are $26.3,-5.3$ and 1.6 respectively, while for the orange-oxidized state (at $+1.8 \mathrm{~V})$ and the $\mathrm{L}^{*} \mathrm{a} * \mathrm{~b} *$ parameters are $45.6,12.9$ and 30.7 , respectively. The contrast $\Delta \mathrm{E}^{*}=$ $\left[\left(\mathrm{L}^{*} \mathrm{c}-\mathrm{L}_{\mathrm{b}}\right)^{2}+\left(\mathrm{a}_{\mathrm{c}}-\mathrm{a}_{\mathrm{b}}\right)^{2}+\left(\mathrm{b}_{\mathrm{c}}{ }_{\mathrm{c}}-\mathrm{b}_{\mathrm{b}}\right)^{2}\right]^{1 / 2}$ is of 39.4

The electrochemical activity of the $\mathrm{V}_{2} \mathrm{O}_{5}$ films in a $\mathrm{Li}^{+}$based electrolyte, namely $0.3 \mathrm{M}$ LiTFSI-BMITFSI, was compared with the intercalation/deintercalation process in a $\mathrm{Na}^{+}$ containing electrolyte, namely $0.3 \mathrm{M}$ NaTFSI-BMITFSI. The CVs of the $\mathrm{V}_{2} \mathrm{O}_{5}$ in the $0.3 \mathrm{M}$ NaTFSI-BMITFSI electrolyte in the -0.4 to $+1.8 \mathrm{~V}$ range show a nice reversible behavior over 50 cycles (Fig. 8) with however a slight loss of capacity of $2 \%$ after 50 cycles ((inset Fig. 8). Interestingly, the CVs shape differs from cycling in lithium based electrolyte with the signature of a main oxidation peak in oxidation closer to the "duck" shape, even for lower cycling rates (i.e. down to $5 \mathrm{mV} / \mathrm{s}$ ) (Fig. 9a). Such behavior should be correlated to the larger sodium cation size $\left(\mathrm{r}^{\mathrm{Na}+}>\mathrm{r}^{\mathrm{Li}+}\right)$ in agreement with less defined insertion sites as well as larger surface reaction. Interestingly, the $\mathrm{Na}$ insertion/reaction in $\mathrm{V}_{2} \mathrm{O}_{5}$ has received recent attention in the literature in particular in the field of $\mathrm{Na}$ batteries [32]. Surprisingly, higher capacity values were recorded when cycling in Na based electrolyte.

Another discrepancy with cycling in Li based electrolyte, lies in the evolution of the CV shape with scan rate from $50 \mathrm{mV} / \mathrm{s}$ to $5 \mathrm{mV} / \mathrm{s}$ (Figs. 6a and 9a). On the contrary of Li based electrolyte, no visible peaks clearly appear with decreasing scan rate. The linear relationship 
of the anodic peak current density $\left(\mathrm{j}_{\mathrm{a}}\right)$ with the square root of scanning rate $\left(\mathrm{V}^{1 / 2}\right)($ Fig. $9 \mathrm{~b})$

226 leads to the determination of the diffusion coefficient $\mathrm{D}_{\mathrm{Na}}+=4.28 * 10^{-8} \mathrm{~cm}^{2} / \mathrm{s}$. A higher

227

228 electrochemical response (i.e. an increase in capacity) using $\mathrm{Na}$ based electrolytes was also observed when comparing the cycling behavior in $\mathrm{LiCl}$ and $\mathrm{NaCl}$ aqueous electrolytes. The origin of the higher capacity in $\mathrm{Na}$ based electrolyte as compared to lithium one remains unclear however for ionic liquids based electrolytes higher ionic conductivity was recorded for PMMA membranes containing NaTFSI in BMITFSI as compared to LiTFSI in BMITFSI. Besides, handling of the preparation of our devices in air is likely to be associated with traces of water in the electrolyte of which presence may induce some water adsorption at the film surface.

The reflectance spectra for $\mathrm{V}_{2} \mathrm{O}_{5}$ films corresponding to the oxidized and reduced states, recorded before and after $100 \mathrm{CA}$ cycles are presented in Fig. 10. The reduced green state ($0.4 \mathrm{~V} / 120 \mathrm{~s})$ and the oxidized orange-brownish state $(+1.8 \mathrm{~V} / 120 \mathrm{~s})$ are associated with reflectance values of about $\mathrm{R}_{\mathrm{G}} \approx 4 \%$ and $\mathrm{R}_{\mathrm{O}} \approx 15 \%$ at $630 \mathrm{~nm}$, respectively, corresponding to a reflectance modulation $\Delta \mathrm{R}$ of $11 \%$. After 100 cycles, despite the slight decrease in capacity, an increase of the reflectance modulation, $\Delta \mathrm{R}=17 \%$, corresponding to $\mathrm{R}_{\mathrm{C}} \approx 3.5 \%$ and $\mathrm{R}_{\mathrm{B}} \approx$ $20.5 \%$ at $630 \mathrm{~nm}$, is observed. In addition, from chronoamperometry measurements (not shown here), the switching time between a reduced and an oxidized state in the case of $\mathrm{Na}$ based electrolyte is of about $9 \mathrm{~s}$ and $7 \mathrm{~s}$ respectively, while it is of about $11 \mathrm{~s}$ and $9 \mathrm{~s}$ for $\mathrm{Li}$ based electrolyte confirming the trend discussed above of faster diffusion in $\mathrm{Na}$ based electrolyte.

\section{Electrochromic performance of $\mathrm{V}_{2} \mathrm{O}_{5}$ based ECD}

In a final step, an ECD was built, from the association of $\mathrm{WO}_{3}$ and $\mathrm{V}_{2} \mathrm{O}_{5}$ films, using anhydrophobic electrolyte membrane based on 0.3 M LiTFSI-BMITFSI in PMMA as ion 
conductor. $\mathrm{WO}_{3}$ films were deposit by the "Doctor Blade" from commercial Aldrich powder. The transparent viscous mixture of ionic liquid in $40 \%$ in PMMA was spread under ambient atmosphere on the $\mathrm{WO}_{3}$ and $\mathrm{V}_{2} \mathrm{O}_{5}$ electrochromic layers using a syringe and dried for 2 hours at $80^{\circ} \mathrm{C}$ under vacuum ( $100 \mathrm{~Pa}$.) to remove butanone leading to hydrophobic, sticky lithium conducting electrolyte membranes. Prior to device assembly, $\mathrm{WO}_{3}$ thin film was cycled in 0.3 M LiTFSI-BMITFSI electrolyte for five cycles and assembled in the blue reduced state state to the pre-cycled $\mathrm{V}_{2} \mathrm{O}_{5}$ counter electrode.

The shape of the cyclic voltammogramms of the $\mathrm{Li}_{\mathrm{x}} \mathrm{WO}_{3} /$ LiTFSI-BMITFSI in PMMA/ $/ \mathrm{V}_{2} \mathrm{O}_{5}$ illustrates a well reversible behavior with good cyclability associated with a nice switch from orange to green for the $\mathrm{V}_{2} \mathrm{O}_{5}$ thin film (Fig. 11). Interestingly, the capacity slightly increases upon early cycling (inset Fig. 11) while it is of $20 \mathrm{mC} / \mathrm{cm}^{2}$ after 200 cycles

The ex-situ evolution of the reflectance spectra for $\mathrm{V}_{2} \mathrm{O}_{5} /$ electrolyte/ $\mathrm{WO}_{3}$ device is depicted in (Fig. 12). The reduced-green state $(-1.5 \mathrm{~V} / 60 \mathrm{~s})$ and the oxidized-orange state at $(+1.5 / 60 \mathrm{~s})$ are associated with reflectance values of about $\mathrm{R}_{\mathrm{G}} \approx 9.4 \%$ and $\mathrm{R}_{\mathrm{O}} \approx 21.6 \%$ at 630 $\mathrm{nm}$, respectively, with a total reflectance modulation of $\Delta \mathrm{R} \approx 12.2 \%$. In addition similar properties remain after 200 cycles, $\mathrm{R}_{\mathrm{G}} \approx 10.9 \%$ and $\mathrm{R}_{\mathrm{O}} \approx 22.3 \%$ at $630 \mathrm{~nm}$, leading to a reflectance modulation of $\Delta \mathrm{R} \approx 11.4 \%$.

The switching optical response in between alternating potentials is a key characteristic of electrochromic devices. Switching times were deduced from monitoring the reflectance at a wavelength of $550 \mathrm{~nm}$ under the application of voltages of $-1.5 \mathrm{~V}$ and $1.5 \mathrm{~V}$ for $60 \mathrm{sec}$. The switching time between a reduced green state $(-1.5 \mathrm{~V})$ and an oxidized-orange state $(+1.5 \mathrm{~V})$ is of about $8 \mathrm{~s}$ and increases upon cycling as the drop in reflectance is smoothen after 200 cycles (Fig. 13). Upon reduction, the switching time strongly increases from 8 to $29 \mathrm{~s}$ while in oxidation the increase is only from 7 to $10 \mathrm{~s}$. The origin of such increase remains unclear but might be ascribed to a modification of the film morphology upon cycling. 


\section{Conclusion}

$\mathrm{V}_{2} \mathrm{O}_{5}$ films were deposited by the Doctor Blade method on ITO substrates from home made $\mathrm{V}_{2} \mathrm{O}_{5}$ powder synthesized by polyol process. This powder, constituted of submicrometric crystallites with a hierarchical structuration, allows to obtain opaque and porous films, i.e. with an adequate morphology besides electrochromic activity. The electrochromic properties of $\mathrm{V}_{2} \mathrm{O}_{5}$ films were demonstrated in $\mathrm{Li}$ and $\mathrm{Na}$ based electrolytes, showing in both cases a nice reversibility in between green and orange states corresponding to a modulation in reflectance of $15-20 \%$ at $630 \mathrm{~nm}$. The switching properties appeared to be associated with a more bulk/insertion process in the case of $\mathrm{Li}$ and a more surface process in the case of $\mathrm{Na}$. Further investigations are in progress to better understand the differences associated with both electrolytes. Electrochromic activity was used to build $\mathrm{V}_{2} \mathrm{O}_{5}$ /electrolyte/ $\mathrm{WO}_{3}$ devices exhibiting nice reflectance modulation suitable for display application. In addition, current investigations on $\mathrm{Ti}-\mathrm{V}_{2} \mathrm{O}_{5}, \mathrm{Mo}, \mathrm{W}$, demonstrate the benefit of the polyol process for producing high quality doped powders with specific morphologies, of which properties will be reported in the future.

. 


\section{References}

[1] Y. Yang, D. Kim, P. Schmuki, Electrochem. commun. 13 (2011) 1198-1201.

[2] A.Šurca Vuk, M. Koželj, B. Orel, Sol. Energy Mater. Sol. Cells 128 (2014) 166-177.

[3] A. Danine, L. Cojocaru, C. Faure, C. Olivier, T. Toupance, G. Campet, A. Rougier, Electrochim. Acta 129 (2014) 113-119.

[4] S.F. Cogan, N.M. Nguyen, S.J. Perrotti, R.D. Rauh, J. Appl. Phys. 66 (1989) 1333-1337.

[5] C.G. Granqvist, Handbook of Inorganic Electrochromic Materials, 2nd Ed., Elsevier, Amsterdam, 2002.

[6] L. Sziráki, L. Bóbics, Electrochim. Acta, 47 (2002) 2189-2197.

[7] R.T. Wen, G.A. Niklasson, C.G. Granqvist, Sol. Energy Mater. Sol. Cells120 (2014) 151-156.

[8] P.S. Patil, R.K. Kawar, S.B. Sadale, A.I. Inamdar, S.S. Mahajan, Sol. Energy Mater. Sol. Cells 90 (2006) 1629-1639.

[9] X.H. Xia, J.P. Tu, J. Zhang, X.L. Wang, W.K. Zhang, H. Huang, Sol. Energy Mater. Sol. Cells 92 (2008) 628-633.

[10] K.K. Purushothaman, G. Muralidharan, Materials Science in Semiconductor Processing, 14 (2011) 78-83.

[11] X. Lou, X. Zhao, X. He, Solar Energy, 83 (2009) 2103-2108.

[12] G. Bodurov, P. Stefchev, T. Ivanova, K. Gesheva, Mater. Lett. 117 (2014) 270-272.

[13] H. Moulki, D.H. Park, B.K. Min, H. Kwon, S.J. Hwang, J.H. Choy, T. Toupance, G.

Campet, A. Rougier, Electrochim. Acta 74 (2012) 46-52.

[14] Q. Wei, J. Liu, W. Feng, J. Sheng, X. Tian, L. He, Q. Anb, L. Mai, Mater.Chem. A, 3 (2015) 8070-8075.

[15] N.A. Chernova, M. Roppolo, A.C. Dillon, M.S. Whittingham, J. Mater. Chem., 19(2009) 2526-2552.

[16] C. Denga, S. Zhang, Z. Dong, Y. Shang, Nano Energy 4 (2014) 49-55. 
[17] L. Li, U.Steinera, S. Mahajan, J. Mater. Chem., 20 (2010) 7131-7134.

[18] Z. Tong, X. Zhang, H. Lv, N. Li, H. Qu, J. Zhao, Y. Li, X.Y. Liu, Adv. Mater. Interfaces $2(2015) 1500230$

[19] Z. Tong, H. Lv, X. Zhang, H. Yang, Y. Tian, N. Li, J. Zhao, Y. Li, Sci. Rep. 5 (2015) 16864.

[20] Z. Tong, J. Hao, K. Zhang, J. Zhao, B-L. Suc, Y. Li,J. Mater. Chem. C, 2 (2014) 36513658.

[21] W. Kang, C. Yan, X. Wang, C.Y. Foo, A.W.M. Tan, K.J.Z. Chee, P.S. Lee, J. Mater. Chem. C, 2(2014) 4727-4732.

[22] Y. Iida, Y. Kaneko, Y. Kanno, J. Mater. Process. Technol. 197 (2008) 261-267.

[23] P. Liu, S.H. Lee, C.E. Tracy, J. A. Turner, J.R. Pitts, S.K. Deb, Solid State Ionics 165 (2003) 223-228.

[24] R.T.R. Kumar, B. Karunagaran, S. Venkatachalam, D. Mangalaraj, S.K. Narayandass, R. Kesavamoorthy, Mater. Lett. 57 (2003) 3820-3825.

[25] S.H. Lee, H.M. Cheong, P. Liu C.E. Tracy, J.R. Pitts, S.K. Deb, Solid State Ionics 165 (2003)81-87.

[26] E. Cazzanelli, G. Mariotto, S. Passerini, W.H. Smyr, A. Gorenstein, SolEnergy Mater. Sol. Cells 56 (1999) 249-258.

[27] Y. Wei, M. Li, J. Zheng, C. Xu, Thin Solid Films 534 (2013) 446-451.

[28] C.S. Hsu, C.C. Chan, H.T. Huang, C.H.Peng, W.C. Hsu, Thin Solid Films 516 (2008) $4839-4844$.

[29] V.V. Kondalkar, R.R. Kharade, S.S. Mali, R.M. Mane, P.B. Patil, P.S. Patil,S.

Choudhury, P.N. Bhosale, Superlattices and Microstructures 73 (2014) 290-295.

[30] J. Du, L. Jiao, Q. Wu, Y. Liu, Z. Qi, L. Guo, Y. Wang, H. Yuan, Electrochim. Acta 98(2013) 288-293. 
353 [31] J. Xie, T. Tanaka, N. Imanishi, T. Matsumura, A. Hirano, Y. Takeda, O. Yamamoto, J.

354 Power Sources 180 (2008) 576-581.

355 [32] E. Uchaker, Y. Z. Zheng, S. Li, S. L. Candelaria, S. Hu and G. Z. Cao, J. Mater. Chem. A $356 \quad 2$ (2014) 18208-18214.

357

358 